\title{
DESIGN SUSTENTÁVEL OU SOCIAL? COMO OS DESIGNERS QUE FAZEM PROJETOS PARA INCLUSÃO SOCIAL E DESENVOLVIMENTO SUSTENTÁVEL CARACTERIZAM SEU TRABALHO
}

\section{Mônica Maranha Paes de Carvalho, MSc. (UnB); Orientador: Alfredo Jefferson de Oliveira, Dr. (PUC-Rio)}

\section{INTRODUÇÃO}

Nos últimos anos, uma quantidade significativa de designers no Brasil faz capacitações e consultorias com grupos de produção artesanal, frequentemente em situação de vulnerabilidade. Nota-se que os projetos muitas vezes são associados ao objetivo de promover inclusão social e desenvolvimento sustentável quando descritos em seus materiais de divulgação, em artigos ou em premiações das quais participam.

A partir desses indícios, colocam-se algumas perguntas: Como os próprios designers envolvidos nesses projetos caracterizam sua atuação? Será que definem seus trabalhos como "design sustentável"? Ou preferem as denominações "design social" ou até mesmo "ecodesign"? E como são as metodologias usadas?

Este trabalho apresenta os resultados de uma pesquisa de mestrado vinculada ao Programa de Pós-graduação em Design da PUC-Rio. Foi realizada uma pesquisa qualitativa, na qual se entrevistou onze designers que atuam em diferentes partes do Brasil. Os projetos mencionados nos depoimentos aconteceram nos estados do Acre, Amapá, Amazonas, Bahia, Ceará, Espírito Santo, Goiás, Mato Grosso, Minas Gerais, Paraná, Pernambuco, Rio de Janeiro, São Paulo e no Distrito Federal.

Os procedimentos da pesquisa de campo foram tomados com base no Método de Explicitação do Discurso Subjacente (MEDS), desenvolvido por Nicolaci-da-Costa (2007).

Os entrevistados discorreram sobre suas metodologias de trabalho, o relacionamento com as pessoas dos grupos produtivos, dificuldades e facilidades dos projetos e os impactos sociais percebidos. Mencionaram grupos de artesãos, costureiras, tecelãs, artistas plásticos, catadores, pescadores, mães, jovens, quilombolas e indígenas.

A análise das respostas indica que os designers entrevistados utilizam diferentes expressões para designar sua área de atuação: design socioambiental, design com foco no ser humano, design responsável e consciente e, principalmente, design social. Apesar de lidar com questões que são comumente relacionadas ao tema do desenvolvimento sustentável - uso de matérias-primas locais, aproveitamento de refugos industriais, geração de renda, valorização de identidades culturais, melhoria da qualidade de vida e desenvolvimento local - a maior parte dos entrevistados não costuma usar os termos design sustentável ou design para sustentabilidade para designar seu trabalho.

Foi possível ver a ligação que os produtos feitos pelos grupos atendidos têm com a identidade cultural de quem os confecciona, com os valores locais, com as tradições, com as características do território etc. São itens que se tornam relevantes dentro da perspectiva de se tentar projetar, produzir e consumir de forma consciente e responsável.

Sendo assim, independente de levar a qualificação "sustentável", "social" ou qualquer outra dentre as mencionadas, todos os designers entrevistados mostraram uma característica em comum: a preocupação em serem conscientes e responsáveis quanto a seu trabalho. 


\section{REFERÊNCIAS}

1. NICOLACI-DA-COSTA, A. M. O campo de pesquisa qualitativa e o Método de Explicitação do Discurso Subjacente (MEDS). Psicologia: Reflexão \& Crítica, Porto Alegre, v. 20, n.

Quatro entrevistados atuam como consultores em diferentes regiões do Brasil.
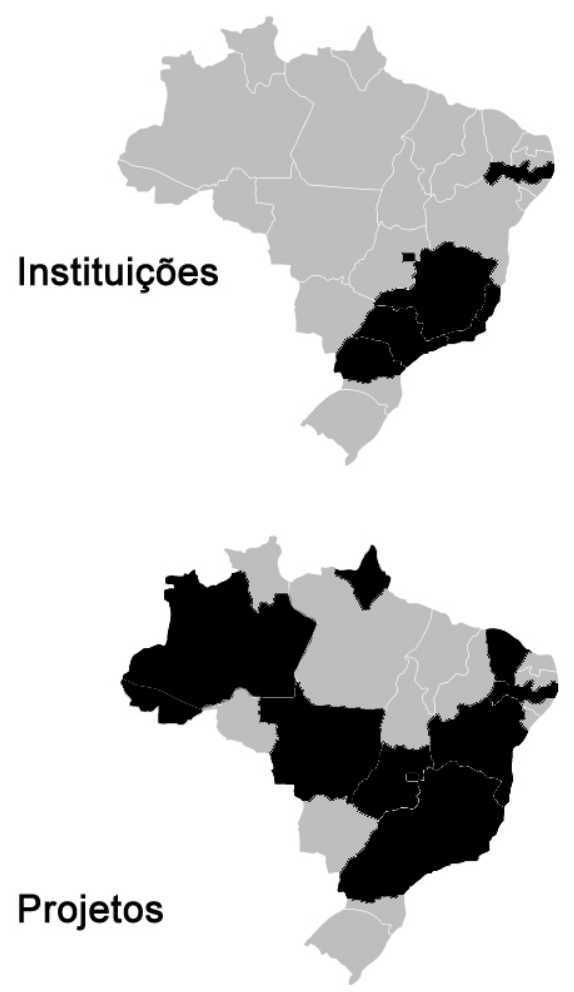

Os demais pertencem (ou pertenciam) a instituições sediadas nos seguintes estados: Espírito Santo, Minas Gerais, Paraná, Pernambuco, Rio de Janeiro, São Paulo e no Distrito Federal.

Os projetos descritos foram executados em diversos estados brasileiros - Acre, Amapá, Amazonas, Bahia, Ceará, Espírito Santo, Goiás, Mato Grosso, Minas Gerais, Paraná, Pernambuco, Rio de Janeiro, São Paulo e no Distrito Federal.

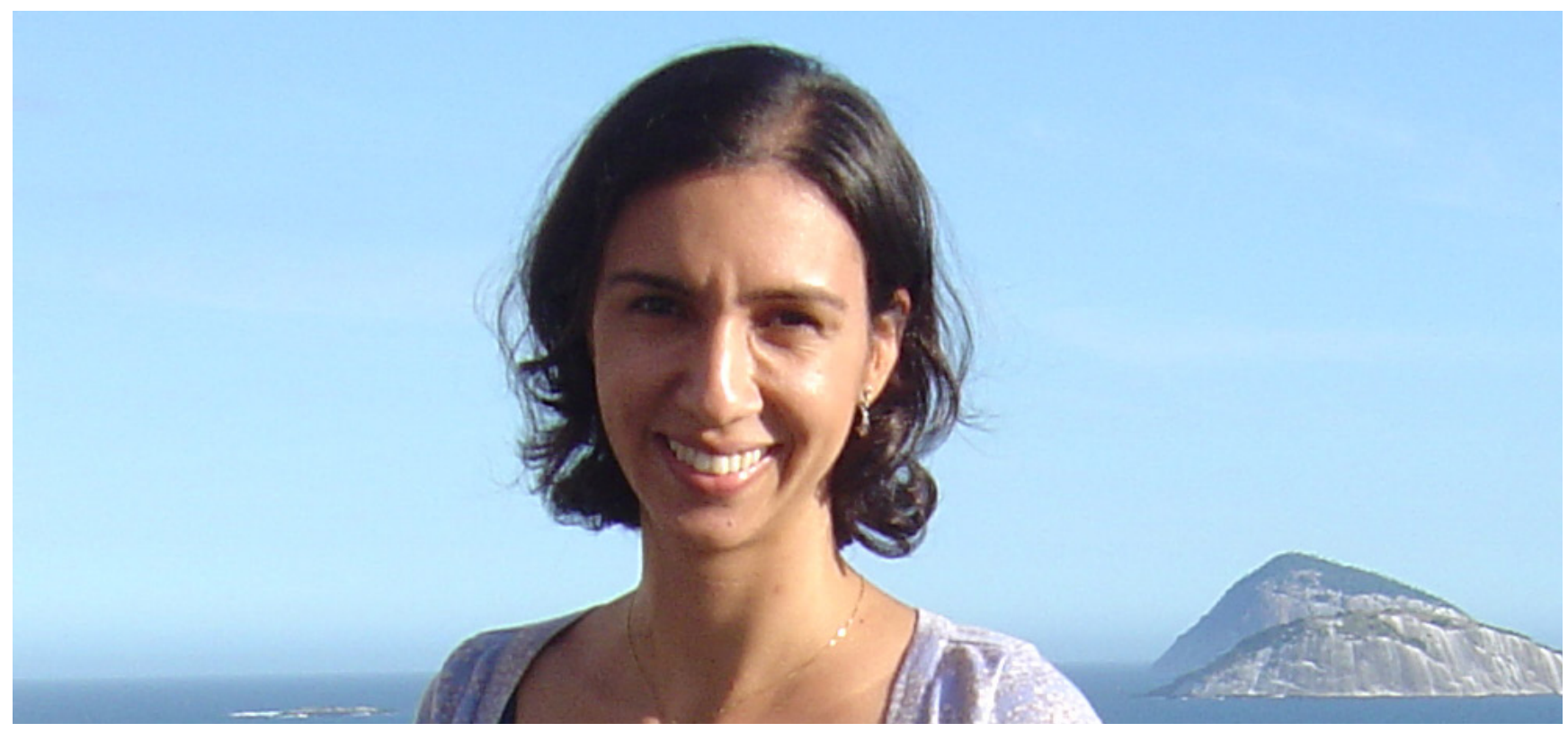

